\title{
Investigation of an Elevator Call Strategy
}

\author{
Yi-Shyan Goh ${ }^{1}$, Muhammad Latif ${ }^{1, *}$, Mian Awais ${ }^{2}$ \\ ${ }^{1}$ School of Engineering, Manchester Metropolitan University, Manchester, UK \\ ${ }^{2}$ Dept. of Computer Science, Syed Babar School of Science \& Engineering, LUMS, Lahore, Pakistan \\ *Corresponding Author: M.Latif@mmu.ac.uk
}

Copyright @ 2013 Horizon Research Publishing All rights reserved.

\begin{abstract}
This paper attempts to describe the simulation of the lift call strategy used by a passenger lift within a university building. The purpose of this study is to devise and develop strategies to enhance the current lift operations by reducing the average waiting time of passengers. A base model was developed to mimic the actual lift system and different approaches were carried out to meet the project aims. The simulation was done by using WITNESS software. The lift is in high demand during the interchange of classes and also at lunch time. It was observed that the lift experienced heavier traffic in the time between 9:00AM and 1:00PM of the day. Passenger's traffic data was collected manually in that period. After analysing the data, four new lift call strategies were devised. All of the strategies were simulated and results were compared to base model. Among the strategies, the strategy that incorporated the car to wait at the unloaded floor appeared to produce the best results as it reduced the average waiting time by $4.4 \%$.
\end{abstract}

Keywords Lift, Elevator, Witness, Simulation

\section{Introduction}

Passenger lifts are a mandatory requirement in buildings with multiple floors [1]. The primary function of a lift is to service passenger requests while optimising the overall service quality [2]. Passengers often experience lift congestion as a result of heavy traffic at peak times [3]. Waiting for a lift can be one of the main annoyances in the experience with high buildings [4]. Ways to improve the efficiency of lift transportation systems in public buildings has become a significant problem for practical applications [5], especially during the up-peak hours [6,7].

The project was inspired by a lift congestion problem in John Dalton East Building, Manchester Metropolitan University, Manchester, UK [8]. It was noticed that the lift (single car) in this building is in high demand during office hours, and has often resulted in long waiting time of passengers. Therefore, an efficient lift system was required to solve the problem. The project was aimed to simulate the current lift dispatching system and devise new strategies to enhance the system.

At the early stage, research on available literature was done to study the background and concepts for different types of lift dispatching systems. To obtain realistic usage data, a survey was conducted to collect passenger traffic data. Following from this, new strategies were devised after analysing the data collected in order to produce an efficient lift dispatching system.

WITNESS simulation software [9] was chosen as a suitable tool to model and simulate the lift system. After an investigation and suitable data collection a base model was developed representing the current lift system. New strategies were applied to the model; their results were obtained and compared to determine the best strategy.

\section{Objectives}

To explore strategic changes to the lift call strategy which will reduce the average queue waiting times resulting in higher service levels for passengers. The new strategy is expected to minimize the queues of passengers formed due to the lift congestion problem.

\section{Materials and Methods}

\subsection{Background}

The study concentrates on the lift (Installation Number: MMU Lift 33) in John Dalton East Building. This building consists of 5 floors and houses the Faculty of Science and Engineering at Manchester Metropolitan University. During office hours, the lift is highly demanded, especially during the interchange of lecture classes and also lunch time (9:00AM - 1:00PM).

This is a single-car lift and it can carry up to a maximum of 13 passengers. The current strategy used by the lift is first-come first-serve basis and it does not have a special strategy to handle the peak hours. When the lift responds to a call, it will first look at the direction of travel. The lift will then respond to the nearest calls with the same direction of travel when it moves towards them and it will park at the 
ground floor when there is no demand.

Students and staffs often use the lift to travel to different floors, but due to the long waiting time, some of the passengers decide to use the stairs. It can be argued that the lift is not serving its purpose efficiently. Therefore, it is necessary to devise a better strategy to tackle the lift congestion problem during the peak time.

\subsection{Data Collection Method}

In order to collect a set of realistic data, a field study was carried out. The passenger's traffic data was collected through observation inside the lift as well as at the floor call points. Data such as the arrival time of passengers was obtained at the call point on each floor. Whereas the source and destination of passengers was collected through observation inside the car.

It was observed that the lift experienced heavier traffic in the time between morning classes and lunch time (9:00AM 1:00PM) of the day. Since the project aim is to tackle the lift congestion problem, therefore only data in the peak hours was collected. A survey was conducted to gather the usage of the lift.

\subsection{Collected Data}

\subsubsection{Arrival Data}

Table 1 shows the maximum arrivals of different passengers at each floor observed and tabulated during the up-peak.

Table 1. Maximum arrival of Passengers

\begin{tabular}{|c|c|c|c|}
\hline Passenger & $\begin{array}{c}\text { Maximum } \\
\text { Arrivals }\end{array}$ & Passenger & $\begin{array}{c}\text { Maximum } \\
\text { Arrivals }\end{array}$ \\
\hline G_1 $1^{\text {st }}$ & 3 & Second_3 $3^{\text {rd }}$ & 1 \\
\hline $\mathrm{G} 2_{2} \mathrm{n}^{\text {nd }}$ & 12 & Second_ $4^{\text {th }}$ & 3 \\
\hline $\mathrm{G} \_3^{\text {rd }}$ & 77 & Third_G & 50 \\
\hline $\mathrm{G}_{-} 4^{\text {th }}$ & 74 & Third_1 ${ }^{\text {st }}$ & 2 \\
\hline First_G & 3 & Third_2 $2^{\text {nd }}$ & 3 \\
\hline First_2 $2^{\text {nd }}$ & 1 & Third_4 $4^{\text {th }}$ & 4 \\
\hline First_3 $3^{\text {rd }}$ & 4 & Fourth_G & 59 \\
\hline First_ $4^{\text {th }}$ & 4 & Fourth_1 $1^{\text {st }}$ & 8 \\
\hline Second_G & 12 & Fourth $\_2^{\text {nd }}$ & 6 \\
\hline Second_1 $1^{\text {st }}$ & 1 & Fourth_3 $3^{\text {rd }}$ & 6 \\
\hline
\end{tabular}

\subsubsection{Car Travelling Time}

The travelling time of the car is needed to determine the car travelling speed in the simulation model. The duration of travel was timed using a stopwatch, the results are shown in table 2 .
Table 2. Car Travelling Time

\begin{tabular}{|c|c|}
\hline Floor & Time taken (second) \\
\hline Ground Floor $-1^{\text {st }}$ Floor & 5.27 \\
\hline $1^{\text {st }}$ Floor $-2^{\text {nd }}$ Floor & 5.10 \\
\hline $2^{\text {nd }}$ Floor $-3^{\text {rd }}$ Floor & 4.72 \\
\hline $3^{\text {rd }}$ Floor $-4^{\text {th }}$ Floor & 5.02 \\
\hline Average Value & 5.03 \\
\hline
\end{tabular}

From table 2, the computed average travelling time was used within the model.

\subsubsection{Loading and Unloading Time}

The loading and unloading time includes the opening and closing time of lift doors as well as the time for passengers to go in and get out from the lift. Again, the duration was timed using a stopwatch, results are shown in Table 3 and Table 4.

Table 3. Passenger loading time

\begin{tabular}{|c|c|}
\hline Floor & Time taken (seconds) \\
\hline Ground Floor & 5.36 \\
\hline $1^{\text {st }}$ Floor & 4.63 \\
\hline $2^{\text {nd }}$ Floor & 4.72 \\
\hline $3^{\text {rd }}$ Floor & 4.91 \\
\hline $4^{\text {th }}$ Floor & 4.80 \\
\hline Average Value & 4.884 \\
\hline
\end{tabular}

Table 4. Passenger unloading time

\begin{tabular}{|c|c|}
\hline Floor & Time taken (seconds) \\
\hline Ground Floor & 5.51 \\
\hline $1^{\text {st }}$ Floor & 4.52 \\
\hline $2^{\text {nd }}$ Floor & 4.70 \\
\hline $3^{\text {rd }}$ Floor & 4.89 \\
\hline $4^{\text {th }}$ Floor & 4.84 \\
\hline Average Value & 4.892 \\
\hline
\end{tabular}

As seen from tables $3 \& 4$, the average loading/unloading times are very similar which were used in the model.

\subsection{Modelling}

In order to obtain realistic results, the lift was modelled and run with the same strategy as it is. The model mimics the real life scenario where the lift has 5 stops and responds to passenger calls in first-come first-serve basis. Initially, the lift will look at the direction of travel and it will then respond to the nearest calls with the same direction of travel when it moves towards them. Since the lift experienced heavier traffic in the time between 9:00AM and 1:00PM, only data in those hours was applied to the model. 


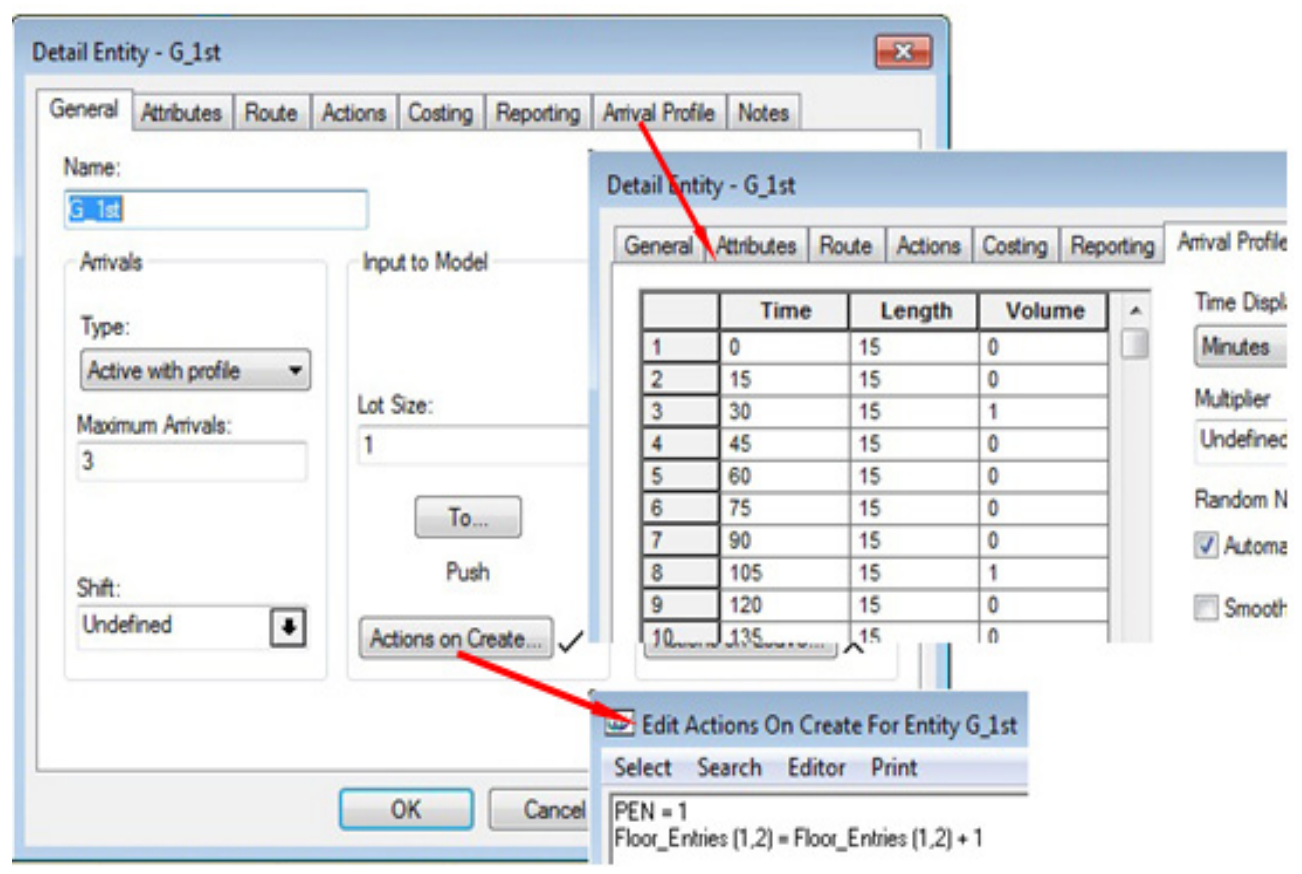

Figure 1. Arrival of passengers into model

\subsubsection{WITNESS Elements}

Modelling begins with the use of elements according to the requirements. Table 5 maps the WITNESS elements with the real life system.

Table 5. Mapping of Witness elements

\begin{tabular}{|c|c|c|}
\hline Element & Names in model & Represents \\
\hline Entity & G__1st, First_2 ${ }^{\text {nd }}$ etc. & Passengers \\
\hline Queue & Qin, Up, Down etc. & Waiting Points \\
\hline Activity & Batch, Join, Sort etc. & Loading and Unloading Points \\
\hline Track & Floor & Lift Shaft \\
\hline Vehicle & Lift & Car \\
\hline
\end{tabular}

\subsubsection{Modeling of Passengers}

The WITNESS element Entity is used to represent the passengers who used the lift. Table 6 shows the color scheme used to differentiate the passenger's destinations.

Table 6. Identification of Passengers Destination

\begin{tabular}{|c|c|}
\hline Icon & Represents \\
\hline$\square$ & Passengers travelling to Ground Floor \\
\hline$\square$ & Passengers travelling to $1^{\text {st }}$ Floor \\
\hline & Passengers travelling to $2^{\text {nd }}$ Floor \\
\hline & Passengers travelling to $3^{\text {rd }}$ Floor \\
\hline$\square$ & Passengers travelling to $4^{\text {th }}$ Floor \\
\hline
\end{tabular}

Figure 1 shows the details of model element $G_{-}{ }^{s t}$ which represent the passengers arrive at Ground Floor and travel to $1^{\text {st }}$ Floor. Type is set to Active with Profile means the entities will be created according to the Arrival Profile as per data collected. The value of Maximum Arrivals is set to 3 following the data collected and Lot Size $=1$ means one entity will be created at a time. Finally, Actions on Create determine the color of entities (PEN 1-5) according to their destinations and update the Floor_Entries counter values in the model. 


\section{Modelled System}

Figure 2, illustrates the control strategy used in the base model. This strategy is first-come first-serve basis. The lift will load the first passenger and move in the desired direction. If there is a call with the same direction of travel, the lift will load the passenger as it moves towards that floor. With this strategy, the lift will always load and unload passengers at the nearest floor according to the direction of travel.

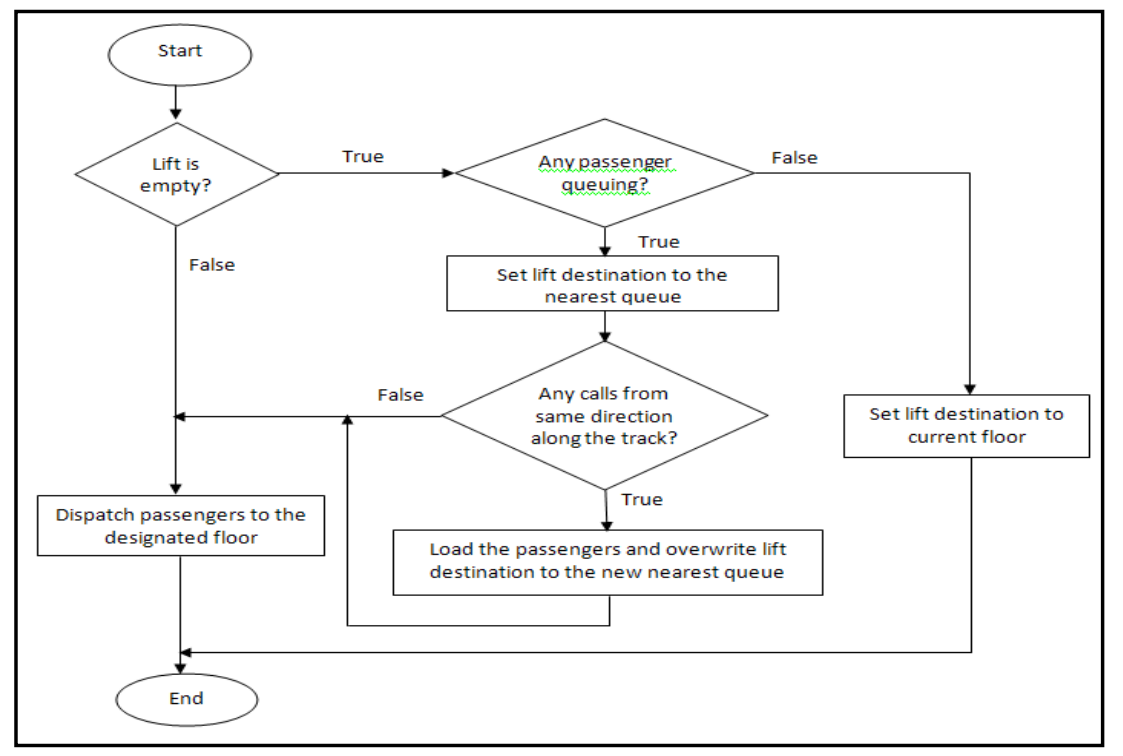

Figure 2. Flowchart of Base Model

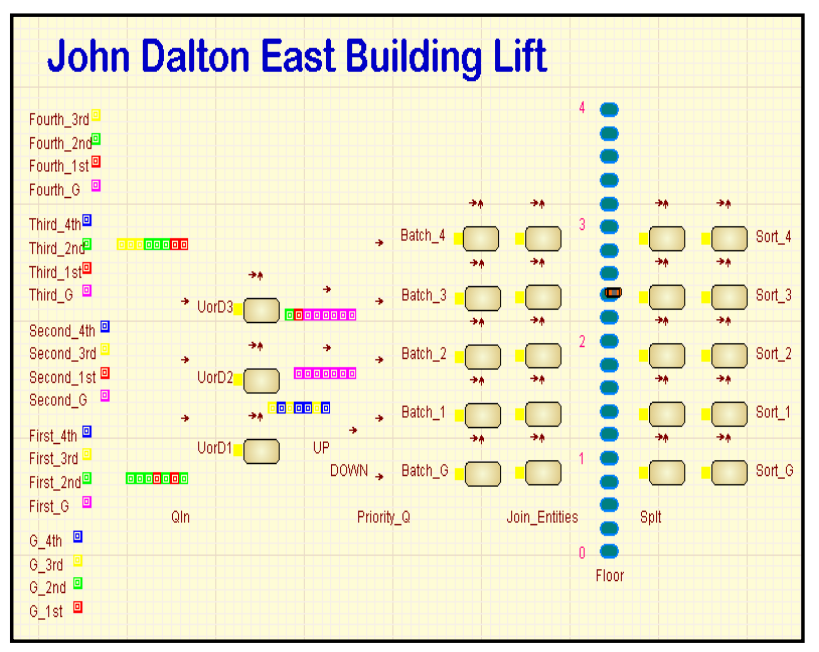

Figure 3. Witness Base Model representing the lift system

\subsection{Base Model}

Figure 3 illustrates the Witness model constructed representing the lift system "as is" and described as the base model. It is suffice to state that verification and validation of the base model was completed. Further details of the Witness constructs and elements used to model the lift system are omitted in this paper as they are the subject of a future paper.

The graphics display of the base model has been developed with some KPI data as shown in figure 4 representing four hours of continuous simulation.

Statistical results obtained from this simulation are presented and discussed in the Results and Discussion section.

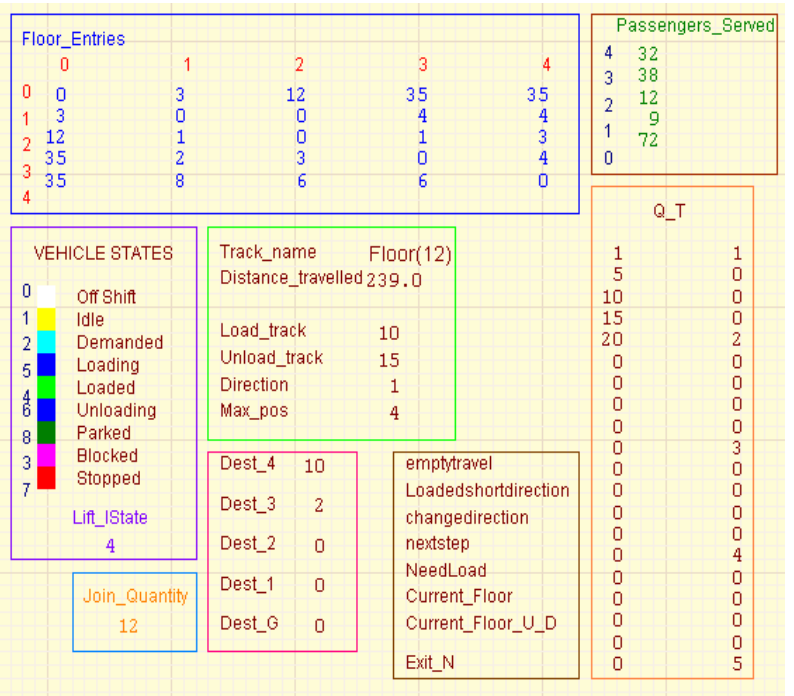

Figure 4. KPI display of Base Model

\subsection{Strategy 1}

The concept of Strategy 1 is to always set the destination of lift in the ascending order of $\mathrm{G}-1^{\text {st }}-2^{\text {nd }}-3^{\text {rd }}-4^{\text {th }}$ Floor. By doing this, Ground Floor will always has the highest priority when the lift sets its destination. Similar to the base model, if there is a call with the same direction of travel, the lift will load the passenger as it moves towards that floor. The lift will then set a new destination using the same order. After unloading all passengers, the lift will park at the unload 
track until a new call is made.

From the data collected in Table 1, it shows that most of the passengers came from the Ground Floor. The concept is to allow the lift get to Ground Floor as frequent as possible. This idea was aimed to increase the number of loadings at Ground Floor in order to reduce the waiting time.

\subsection{Strategy 2}

Strategy 2 is similar to Strategy 1 except the lift will park at $4^{\text {th }}$ Floor when there is no call made.

Following Strategy 1, since Ground Floor has the highest priority when the lift sets its destination, this approach was to let the lift stand-by on $4^{\text {th }}$ Floor in order to balance the number of loadings for higher floors. Strategy 2 is mainly aimed to enhance the Strategy 1 in terms of work distribution at different floors.

\subsection{Strategy 3}

Strategy 3 reversed the destination setting of Strategy 1 to descending order of $4^{\text {th }}-3^{\text {rd }}-2^{\text {nd }}-1^{\text {st }}-G$ Floor. Besides that, similar to Strategy 1 , the car will remain at the same floor after unloading all passengers.

Data collected in Table 1 shows that the second largest volume of the passengers was arriving from $4^{\text {th }}$ Floor other than Ground Floor. This strategy attempts to increase the number of stops at $4^{\text {th }}$ Floor in order to pick up more passengers. Overall, Strategy 4 aims to reduce the waiting time on $4^{\text {th }}$ Floor.

\subsection{Strategy 4}

The only difference between Strategy 3 and Strategy 4 is the car will park at Ground Floor when there is no call made in Strategy 4.

This approach was to balance the number of loadings at lower floors because $4^{\text {th }}$ Floor has the highest priority when the lift sets its destination. The reason Strategy 4 was developed is mainly to focus on the waiting time at Ground Floor because it has the highest maximum arrivals of passengers as shown in Table 1 .

\section{Results}

Table 8 and Table 9 summarize the average waiting time of passengers in queues and statistical results of the lift (vehicle) obtained from the base model and the four different strategies.

Table 8. Summary of average queue waiting time

\begin{tabular}{|c|c|c|c|c|c|c|}
\hline \multirow{2}{*}{ Queue } & \multirow{2}{*}{ Floor } & \multicolumn{5}{|c|}{ Average waiting time (second) } \\
\hline & & Base Model & Strategy 1 & Strategy 2 & Strategy 3 & Strategy 4 \\
\hline QIn(1) & Ground & 88.10 & 90.34 & 90.34 & 88.10 & 88.10 \\
\hline UP(1) & First & 125.46 & 101.71 & 101.71 & 125.46 & 125.46 \\
\hline DOWN(1) & First & 26.44 & 26.44 & 26.44 & 39.10 & 39.10 \\
\hline UP(2) & Second & 42.96 & 42.96 & 42.96 & 42.96 & 42.96 \\
\hline $\operatorname{DOWN}(2)$ & Second & 99.46 & 99.46 & 99.46 & 84.82 & 84.82 \\
\hline UP(3) & Third & 16.66 & 16.66 & 16.66 & 16.66 & 16.66 \\
\hline DOWN(3) & Third & 86.31 & 86.31 & 86.31 & 78.71 & 78.71 \\
\hline \multirow[t]{2}{*}{ Qin(5) } & Fourth & 21.47 & 21.47 & 21.47 & 31.15 & 31.15 \\
\hline & Average & 60.67 & 57.99 & 57.99 & 59.48 & 59.48 \\
\hline
\end{tabular}

From Table 8, it can be seen that Strategy 1 and Strategy 2 obtained a shorter average waiting time among all the strategies when compared to the base model.

Table 9. Lift statistics

\begin{tabular}{|l|l|l|l|l|l|}
\hline & $\begin{array}{l}\text { Base } \\
\text { Model }\end{array}$ & $\begin{array}{l}\text { Strategy } \\
\mathbf{1}\end{array}$ & $\begin{array}{l}\text { Strategy } \\
\mathbf{2}\end{array}$ & $\begin{array}{l}\text { Strategy } \\
\mathbf{3}\end{array}$ & $\begin{array}{l}\text { Strategy } \\
\mathbf{4}\end{array}$ \\
\hline Free (\%) & 15.38 & 15.38 & 15.38 & 12.31 & 12.31 \\
\hline Loaded (\%) & 84.62 & 84.62 & 84.62 & 87.69 & 87.69 \\
\hline $\begin{array}{l}\text { Distance } \\
\text { Travelled (m) }\end{array}$ & 305.00 & 305.00 & 324.00 & 305.00 & 305.00 \\
\hline
\end{tabular}


Table 9 shows that Strategy 1 has a shorter travelled distance compared to Strategy 2. From table 9 it is evident that not all strategies managed to reduce the distance travelled by the car.

\section{Discussions}

Results obtained from all of the strategies show how well the strategies performed in terms of approaching the project objectives. An ideal lift call strategy is expected to provide shorter waiting time than the current system in order to solve the lift congestion problem. Reducing the average waiting time means minimizing the queue crowd formed at the lift. The strategy is also expected to have shorter travelling distance which can reduce the energy consumed by the lift.

Strategy 1 and Strategy 2 fulfill the project aims by reducing the average waiting time from $60.6 \mathrm{~s}$ to $57.9 \mathrm{~s}$, which is $4.4 \%$. However, Strategy 1 has a shorter travelling distance compared to Strategy 2, meaning that Strategy 1 is a better solution because it consumes less energy. Although Strategy 1 did not reduce the travelling distance of base model, but the strategy is able to reduce average waiting time which is the main objective of the project. The results demonstrate that by setting the destination of the car in the ascending order $\left(\mathrm{G}-1^{\text {st }}-2^{\text {nd }}-3^{\text {rd }}-4^{\text {th }}\right)$ this enables a reduction in the average waiting time experienced by passengers at the call points.

Strategy 3 and Strategy 4 can be said to be less successful. These strategies did not manage to reduce the average waiting time. There is no improvement shown in the \%Free and \%Loaded category for the lift.

\section{Conclusion}

The project is a success as the main objectives were achieved by the strategy developed. The survey conducted was able to provide realistic passenger's traffic data to drive the simulation model. The worst time scenario was simulated and different strategies were devised aiming to improve the situation. A total number of four new strategies were devised and tested in the simulation model. All the results obtained from different strategies were compared against the base model. Although some of the strategies did not fulfill the project aims, but useful knowledge was gained.

Strategy 1 is selected as the best solution because it is able to reduce the average waiting time from $60.67 \mathrm{~s}$ to $57.99 \mathrm{~s}$ (4.4\%). Whilst a $4.4 \%$ reduction in the average waiting time may not seem to be significant the practical reality is often very different. Since the model is simulating the travelling experience of over 160 passengers then a reduction in the average waiting time of even $4.4 \%$ is well worth while adopting this change. Other than that, Strategy 1 remains the shortest travelling distance of the lift. Overall, the objectives of project were completed.

\section{REFERENCES}

[1] K. H. Tan, K. Marzuki and Y. Rubiyah. Intelligent elevator control by ordinal structure fuzzy logic algorithm, KES'10, Proceedings of 14th Int conf on Knowledge-based and intelligent information engineering systems, Kuala Lumpur, ISBN: 3-642-14389-5, 2010

[2] X. Yuan, L. Busoniu, and R. Babuska, Reinforcement learning for elevator control, Proceedings 17th IFAC World Congress (IFAC-08), 2212-2217, Seoul, Korea,2008.

[3] J. Horejsi, P. Horejsi, and M. Latif, Strategies for an Elevator Dispatcher System, Modern Machinery (MM) Science Journal, ,234-238, ISSN 1803-1269, July 2011.

[4] A. Tebbenhof, R. Dekker, Econometrics in the elevator. Medium for Econometric Applications, Vol. 9, Edition 3, 26-30, 2000.

[5] P. Cortés, J.R. Fernández, J. Guadix, J.Muñuzuri, Fuzzy Logic based controller for peak traffic detection in elevator systems, Journal of Computational and Theoretical Nanoscience 9 (2), 310-318, 2012.

[6] Y. Lee, T.S. Kim, H.S. Cho, D.K. Sung, B.D. Choi, Performance analysis of an elevator system during up-peak, Mathematical and Computer Modelling vol 49, 423-431, 2009.

[7] H.Y. Tang, W.G. Qi, B. Ding, Prediction of elevator traffic flow based on SVM and phase space reconstruction, Journal of Harbin Institute of Technology, 18 (3), 111-114, 2011.

[8] J. Ahmad, Strategies for an elevator decision support system, MPhil Thesis, Manchester Metropolitan University, Feb 2011.

[9] Witness, The Lanner Group, www.lanner.com, 2012. 